IZA DP No. 7799

Are Females Scared of Competing with Males?

Results from a Field Experiment

Maria De Paola

Francesca Gioia

Vincenzo Scoppa

December 2013 


\title{
Are Females Scared of Competing with Males? Results from a Field Experiment
}

\author{
Maria De Paola \\ University of Calabria \\ and IZA
}

Francesca Gioia

University of Calabria

Vincenzo Scoppa

University of Calabria

and IZA

\section{Discussion Paper No. 7799 \\ December 2013}

IZA

\author{
P.O. Box 7240 \\ 53072 Bonn \\ Germany
}

\author{
Phone: +49-228-3894-0 \\ Fax: +49-228-3894-180 \\ E-mail: iza@iza.org
}

\begin{abstract}
Any opinions expressed here are those of the author(s) and not those of IZA. Research published in this series may include views on policy, but the institute itself takes no institutional policy positions. The IZA research network is committed to the IZA Guiding Principles of Research Integrity.

The Institute for the Study of Labor (IZA) in Bonn is a local and virtual international research center and a place of communication between science, politics and business. IZA is an independent nonprofit organization supported by Deutsche Post Foundation. The center is associated with the University of Bonn and offers a stimulating research environment through its international network, workshops and conferences, data service, project support, research visits and doctoral program. IZA engages in (i) original and internationally competitive research in all fields of labor economics, (ii) development of policy concepts, and (iii) dissemination of research results and concepts to the interested public.
\end{abstract}

IZA Discussion Papers often represent preliminary work and are circulated to encourage discussion. Citation of such a paper should account for its provisional character. A revised version may be available directly from the author. 


\section{ABSTRACT}

\section{Are Females Scared of Competing with Males? Results from a Field Experiment}

We conducted a field experiment involving 720 Italian undergraduate students to investigate the existence of gender differences in performance in competitive settings and whether performance is affected by one's opponent gender. The experimental design was aimed at disentangling gender differences in taste for competition from other differences in psychological attitudes, such as self-confidence and risk aversion. Students were invited to undertake a midterm exam under a tournament scheme having as a prize some bonus points to add to the final grade. Students competed in pairs of equal predicted ability but different gender composition. We find that females are as likely as males to take part in the competition and to obtain a good performance. The gender of one's competitor does not play any role in shaping students' behavior. Men and women perform similarly both in the competitive and in the non-competitive environment.

JEL Classification: J16, J24, J70, C93

Keywords: gender differences, attitude toward competition, psychological differences, tournaments, field experiment, student achievements

Corresponding author:

Maria De Paola

Department of Economics, Statistics and Finance

University of Calabria

Via Ponte Bucci

87036 Arcavacata di Rende (CS)

Italy

E-mail:m.depaola@unical.it

\footnotetext{
* We are grateful to the Dean of the Faculty of Economics at the University of Calabria for allowing us to carry out the experiment, to Sara Laurita and Antonella Caparelli for helping in the use of the data. We would like to thank Pamela Campa, Alessandra Casarico, Adriana Di Liberto, Stefano Gagliarducci, Sabrina Giordano, Paolo Naticchioni, Michela Ponzo, Paola Profeta, for useful comments and suggestions. Maria De Paola and Vincenzo Scoppa acknowledge financial support from MIUR- PRIN 2009 project 2009MAATFS 001. Francesca Gioia gratefully acknowledges financial support from Regione Calabria (European Social Fund).
} 


\section{Introduction}

Men and women continue to differ in many social and economic outcomes: employment perspectives, earnings, job career, access to highly paid jobs and top positions, field of study choice, participation in political activities, and so on (Altonji and Blank, 1999; Bertrand and Hallock, 2001; Blau and Kahn, 2003; Goldin et al., 2006).

A recent strand of the literature goes beyond the traditional explanations based on statistical and taste discrimination and traces the causes of the gender gap in labor market outcomes in differences in psychological attitudes and preferences. According to a number of recent studies women are more riskaverse, less confident, more altruistic and more reluctant to engage in competitions (Bertrand, 2010).

Gender differences in attitudes toward competition have received particular attention and have been explored by many studies in recent years. Three main questions have been investigated in this literature: are women less likely to choose competitive settings than men? Are women less effective in competitions compared to men? Do women under-perform when they compete against men?

Some laboratory studies suggest that women, even the most able, prefer to stay away from competitive environments. Furthermore, these studies show that women taking part to a competition systematically under-perform relative to men (even if they are able to perform similarly to men in noncompetitive situations) and that the female disadvantage is particularly large when females compete against males rather than against other females. On the other hand, results from field experiments are mixed: while some works confirm that in real life situations women underperform relative to men in competitive settings, other studies do not find any gender difference in performance. ${ }^{1}$

In this paper, we try to shed some more light on gender differences in competitive environments and on the role played by one's opponent gender. We study both the individuals' propensity to participate in a competition and their performance in competitive settings. At this aim we conducted a field experiment introducing competitive pressure in the context of a university exam. The experiment involved 720 undergraduate students enrolled at an Italian university and attending three economic courses in the academic year 2012-2013.

We proposed students to take part in a tournament, in which they sit a mid-term exam consisting in questions on the first part of their course program. Students accepting to participate in the experiment were matched in pairs within each class on the basis of their predicted performance leading to pairs of students with comparable ability. Since students were matched independently from their gender we ended up with single-sex and mixed sex couples of competitors. Within each pair the student getting the highest mark at the mid-term exam obtained a bonus of 5 points to add to the grade gained at the final exam; on the other hand,

\footnotetext{
${ }^{1}$ We refer to three extensive reviews for detailed information: Croson and Gneezy (2009); Bertrand (2010); Niederle and Vesterlund (2011).
} 
the student who got the lowest mark obtains a bonus of 2 points (the bonuses were conditional on the reaching of a minimum threshold of $33 \%$ of correct answers).

Students could choose whether to join the experiment with the possibility of obtaining the bonuses or not. At the end of the course, both students participating to the tournament and those deciding to not compete were supposed to take the same final exam covering the entire course program. The final grade was determined either by the points obtained at the final exam (for students not participating in the experiment or not gaining any bonus) or by the sum of final exam points plus the bonus earned at the tournament.

This setting allows us to observe students' performance both in a competitive setting (the mid-term exam), in which students compete one against the other, and in a non-competitive setting (the final exam), where students are rewarded following a sort of piece-rate scheme in which their grade only depends on their own performance.

The design of our experiment has the aim of introducing competition in a real life situation. Compared to laboratory studies, our work has the advantage of considering individuals' performance in a task that is familiar to them and is part of their daily life. While this feature is common to other field studies, differently from the latter we are able to control and neutralize a number of factors that are typically considered as potential explanations of gender differences in competitive environments: a) participants' expectations about their relative abilities; b) risk aversion; c) attitudes toward feedbacks on relative performance; d) stereotypical female or male task. Thus, by ruling out these factors, our experiment is able to provide clean evidence about the "pure" preference of females for competition.

First, in our setting individuals were unlikely to differ in their expectations about their own relative ability because we provided participants with accurate information. In our experiment, an informed subject (students' professor) explained to students that competition would have taken place among competitors of comparable ability, as resulting from their predicted performance based on students' academic achievements and characteristics (high school grade, type of high school, performance at previous related exams and so on). This information should have reassured students that their own ability is as high as their opponents' ability. Gender differences in the degree of confidence should therefore play no role in this setting.

Second, we have tried to propose a risk-free choice. In our setting, final grade at the exam is given by the points earned at the final exam plus the points obtained in the tournament. While in other lab experiments individuals are asked to choose between a piece rate and a tournament (losing the possible reward in the other scheme), in our setting students have the possibility to gain a reward by participating in the tournament without renouncing to the rewards related to the piece-rate scheme.

Third, in our experiment individuals receive a feedback about their performance both in the competitive and in the non-competitive setting, since the grades obtained by all the students are published on line on the courses' webpages, both for the tournament and for the final exam. Publishing on line students' grades is a practice followed in all examination sessions. This rules out the possibility that individuals renounce to participate at the tournament because they dislike to be compared to their peers.

Finally, the task we propose in the tournament - studying economics subjects and answering questions 
about the course program - is not a stereotypical female or male task. Our sample students are enrolled in a Degree Course in Business and Administration which is typically attended by males and females on a quite balanced proportion.

Therefore, our experiment provides new evidence on gender differences in competitive behavior, which might be valuable given the quite mixed results emerging from existing studies. The experimental design should allow us to identify differences occurring because of a different taste for competition between gender.

We firstly focus on participation decisions, which take place in two stages. In a first stage, after experiment rules were announced, students decided whether to join the tournament. In a second stage, after about six weeks, the mid-term exam (i.e. the tournament) took place and students (knowing the identity of their opponent) decided whether to effectively show up at the tournament. About $85 \%$ of students decided to take part in the experiment. However, about $10 \%$ of the students who initially joined the experiment did not show up at the mid-term exam. We do not find gender differences in none of the two participation decisions. Furthermore, we do not find any significant effect of one's opponent gender on the decision of not showing up the day of the tournament.

By analyzing students' performance in the competitive setting, we find that females tend to perform slightly better than males. It also emerges that the gender of the competitor does not produce any statistically significant effect on students' performance. In the final exam (under a piece rate scheme), we again find that females tend to perform better than males. Finally, by comparing each student's performance under the two schemes (with individual fixed effects), we confirm that females do not perform worse (and, if anything, they perform better) than males in competitive settings.

The evidence that we provide suggests that gender differences emerging in other studies is likely driven by differences in risk-aversion, self-confidence and attitude toward feedbacks rather than differences in taste for competition between males and females.

The paper is organized as follows. Section 2 is devoted to a brief discussion of the related literature. In Section 3 we explain the design of the experiment and provide some descriptive statistics. Section 4 investigates students' decision to join the tournament and enter in a competitive setting and analyzes whether one's opponent gender matters for students' decision to withdraw from competition. In section 5 we analyze students' performance at the tournament focusing on the effect produced by one's opponent gender. Section 6 compares for each student the performance obtained in the competitive and in the non-competitive setting. Section 7 concludes.

\section{Related Literature}

A growing literature is devoting attention to gender differences in competitive environments investigating whether women are more reluctant than men to perform in competitive settings and whether they are likely 
to under-perform under competitive pressure.

The tendency of females to avoid competitive environments is well documented in a number of laboratory experiments. Niederle and Vesterlund (2007) let male and female participants experience their own performance in solving a series of additions under a piece-rate scheme (rewards are based only on individual performance) and a tournament scheme (rewards are given on the basis of relative performances). They find that males and females performed similarly in this task under either compensation scheme. However, when they asked participants to choose the incentive scheme for the next task, while 73 percent of men chose the tournament scheme, only 35 percent of women made this choice. Even high-ability women selected themselves into the non-competitive environment. Similar results emerge also from Dohmen and Falk (2006), Niederle and Vesterlund (2011) and Datta Gupta, Poulsen and Villeval (2013).

As regards performance in competitive environments, the first laboratory experimental evidence on gender differences is provided by Gneezy, Niederle and Rustichini (2003) who asked participants to solve mazes in 15 minutes under two different compensation schemes: a piece-rate or non-competitive scheme (in which a payment is received for each maze solved) and a competitive scheme (a "winner-take-all" tournament). They find that males and females performed similarly in non-competitive environments, but females were much less effective than males in competitive environments. Moreover, they find that women performed worse in competitive settings when placed in an all-female group compared to a mixed gender group. $^{2}$

Field experiments give rise to more contrasting results. Whereas some works confirm that in real life situations women underperform relative to men in competitive settings, other studies do not find any gender difference in performance. Gneezy and Rustichini (2004) tested the performance of 9-10 years old boys and girls in a short distance race: in a first round, they let children ran alone; in a second round, children ran in pairs of similar abilities but different gender compositions. The authors do not find gender differences in the speed in the first setting. However, males increased their speed when in competition while females ran slower, leading the males to win $80 \%$ of mixed sex group competitions.

Ors, Palomino and Peyrache (2013) and Jurajda and Munich (2011), using data from entrance exams, respectively, at a highly competitive business school in France and at Czech universities, find that women perform worse under competitive pressure.

In contrast, Lavy (2012) finds no gender based difference in terms of performance and prizes won among high school teachers in a rank-order tournament, in which prizes were based on students' performance. Furthermore, the gender composition of competitors (the pool of teachers in the same school) does not appear to matter. Similarly, Paserman (2010), using data of tennis players in Grand Slam tournaments, finds no differences in the strategy played by men and women in crucial points of the game. In addition, women did not show a more severe deterioration in performance in high pressure situations.

\footnotetext{
${ }^{2}$ Cotton, McIntyre and Price (2013) run an experiment involving five sequential contests and find that, although males outperformed females in the first period contest, no evidence of a male advantage emerged in subsequent periods and females even outperformed males in later periods. Therefore, the authors argue that gender differences may reduce when individuals familiarize with the competitive environment.
} 
Antonovics, Arcidiacono and Walsh (2009), using data from a television game show, find no evidence that the gender of the opponent matters for females' performance in the game, while males performed better against females than against other males. However, replicating the game in the laboratory and changing the stakes, they find that the relative performance of males and females was sensitive to the levels of the stakes. ${ }^{3}$

Gender differences in the propensity to compete and in performance under competitive pressure might be due to differences in taste for competition or depend on other psychological traits typically influencing competition-entry and performance, such as self-confidence (women tend to be less confident than men), attitudes toward risk (women are more risk-averse), or preferences for feedback (women are less eager of feedbacks). In some recent laboratory experiments, researchers have tried to understand the role played by such differences in psychological traits undertaking a number of strategies aimed at neutralizing their effects. For example, a number of papers try to measure beliefs and risk aversion and use them as control variables in regressions (Dargnies, 2009; Balafoutas and Sutter, 2012; Sutter and Rutzler, 2010, Healy and Pate, 2011; Shurchkov 2011). Other works neutralize risk aversion by asking experiment's participants to make a choice characterized by the same risk as the tournament. In the same vein, beliefs are manipulated by changing the task performed by participants ${ }^{4}$ (Niederle and Vesterlund, 2007; Wozniak et al., 2010) or, similarly to what we do in this paper, providing them information on their relative performance (Cason et al., 2010; Wozniak et al., 2010).

Overall, results from these studies show that while risk-aversion does not seem to be relevant in explaining gender differences in competitive environments, differences in beliefs help at explaining these differences. However, gender differences both in entry and in performance in competitive settings tend to remain also controlling for beliefs, suggesting that the taste for competition plays a relevant role (for details, see Niederle and Vesterlund, 2011).

\section{Experiment Description and Data}

The experiment we conducted has involved 720 students enrolled at the courses of Microeconomics, Macroeconomics and Econometrics offered by the Degree Course in Business and Administration at the University of Calabria in the academic year 2012-2013.

The classes were held in the second semester (teaching period from February to June 2013). After the teaching period, students have to sit a written exam (the examination session runs from June to September) aimed at assessing the knowledge of the subject with open questions, mathematical problems and graphical representations. Students can achieve a grade ranging from 0 to 30 cum laude (31) and they pass the exam if

\footnotetext{
${ }^{3}$ Some other works look at competition between teams. Healy and Pate (2011) in a laboratory experiment show that competing in teams leads to about two-thirds reduction in the male-female gap. They also find that the gender of one's teammate does not affect agents' behavior. Opposite evidence emerges from Delfgaauw et al. (2013), who investigate short-term sales competitions among the stores of a Dutch retail chain, finding better performances when the manager and most of the employees have the same gender.

${ }^{4}$ As performance beliefs may change when performing in a stereotypical-female rather than a stereotypical-male task.
} 
the grade is higher or equal to 18 .

University rules in Italy typically do not impose mid-term exams, which are left to the discretion of professors. In the latest years, mid-term exams (giving points that contribute to the final grade) were organized for the courses we consider because they have proved useful to stimulate students to provide effort. $^{5}$

At the beginning of the courses, students were made aware of the possibility to get a bonus, in the form of extra points to add to the final exam grade, by taking part to a mid-term exam organized as a "competition". Students willing to participate were matched in couples on the basis of their predicted ability (see below for details) and the matches were soon communicated to students. After half of the course (late April) matched students sat a mid-term exam consisting of 12 questions about the first part of the program. ${ }^{6}$ The student who gets the highest mark within each pair obtains a bonus of 5 points to add to the final exam grade; the student with the lowest mark obtains a bonus of 2 points. ${ }^{7}$ Bonuses are awarded to students under the condition that at least 4 out of $12(33 \%)$ of answers are correct.

Students not willing to participate take only the final exam. The final exam covers the entire course program, is identical for both students participating and not participating to the competition and allows getting a maximum of 31 points.

The rules of the tournament were explained in detail to students. However, to avoid to influence their behavior ("Hawthorne" and "John Henry" effects) we never mentioned the issue of gender to them.

Students were given one week of time to choose whether to compete for the bonus or not by signing up an online list. About $83 \%$ of the 720 students enrolled in the courses decided to take part in the competition.

Once obtained the list of participating students, we proceeded to the formation of groups of two students competing against each other. We followed a procedure similar to Gneezy and Rustichini (2004) who matched competitors in a speed race by sorting them according to their performance when running alone.

Specifically, using data on students who took the same exams in the previous three academic years we have estimated a model for students' performance (measured by their final grade) using as explanatory variables a vector $X$ of individual characteristics and performance in previous exams: the number of credits earned by students in their academic career, the average grade obtained at exams, the grades at mathematics, statistics and other economics exams, high school grade, type of high school attended, age, province of residence. The estimated coefficients of this model, denoted with the vector $\hat{\pi}$, are then used for predicting the performance of students in our sample on the basis of their effective characteristics:

\footnotetext{
${ }^{5}$ De Paola and Scoppa (2011) analyze the effects of these mid-term exams.

${ }^{6}$ Each question (open, numerical exercise or graphical representation) is worth one point or fraction of it. No penalty is assigned to wrong answers. The time available to students to complete the exam was 60 minutes.

${ }^{7}$ Draws are not allowed: in case of exams with the same score within a pair, a second more careful evaluation is made in order to establish a single winner. In case one student in a pair does not show up at the tournament, the competitor is randomly paired with another student with the same expected ability.
} 


$$
\text { Predicted Grade }_{i}=\hat{\pi}_{0}+\hat{\pi}_{1} X_{1 i}+\ldots+\hat{\pi}_{k} X_{k i}
$$

Finally, ranking students in each course on the basis of their predicted grade, we have formed couples matching the first ranked with the second, the third with the fourth and so on. This assures that competing students have almost the same predicted ability. In this way, we formed three types of groups: female couples, male couples and mixed sex couples.

The pairings were communicated to students the week after the enrollment, through the publication of a list with names and surnames on the courses' webpage. The gender of students was not reported but could be easily identified by their first names.

In each course, all students attended the lectures with the same instructor and teaching material, at the same time and in the same room.

Table 1 provides descriptive statistics for our sample of students. We have information on all 720 students attending the three courses we consider. 125 of them did not participate to the experiment and thus we have 595 participating students. However, 62 of them were absent at the mid-term exam, therefore we are left with 533 students taking part in the competition. ${ }^{8}$

We build two dummy variables to take into account participation decisions: Non participant is a dummy equal to one for students not participating in the experiment (and zero otherwise): 17\% did not participate. Absent is a dummy taking the value of one for students who signed up to participate to the tournament but did not show up the day of the mid-term exam (10\% of students were absent).

\section{Table 1. Descriptive Statistics}

\begin{tabular}{lccccc}
\hline \hline Variables & Obs & Mean & Std. Dev. & Min & Max \\
\hline Non participant & 720 & 0.173 & 0.379 & 0 & 1 \\
Absent & 595 & 0.104 & 0.306 & 0 & 1 \\
Female & 595 & 0.519 & 0.500 & 0 & 1 \\
Econometrics & 595 & 0.272 & 0.446 & 0 & 1 \\
Macroeconomics & 595 & 0.252 & 0.435 & 0 & 1 \\
Microeconomics & 595 & 0.475 & 0.499 & 0 & 1 \\
Female vs. Female & 595 & 0.262 & 0.440 & 0 & 1 \\
Female vs. Male & 595 & 0.257 & 0.437 & 0 & 1 \\
Male vs. Female & 595 & 0.257 & 0.437 & 0 & 1 \\
Male vs. Male & 595 & 0.224 & 0.417 & 0 & 1 \\
High School Grade & 595 & 86.313 & 9.361 & 60 & 100 \\
Lyceum & 595 & 0.508 & 0.500 & 0 & 1 \\
Age & 595 & 20.504 & 2.427 & 18 & 29 \\
Grade Competition & 533 & 0.414 & 0.263 & 0 & 1 \\
Predicted Grade & 533 & 0.332 & 0.204 & 0 & 1 \\
Grade Exam (No competition) & 533 & 0.457 & 0.273 & 0 & 1 \\
\hline \hline
\end{tabular}

Females are 52\%. As regards the gender composition of the couples, about 52\% are mixed sex (Female vs. Male and Male vs. Female), $26 \%$ are single sex female couples, Female vs. Female, and the remaining $22 \%$ are single sex male couples, Male vs. Male. About $27 \%$ and $25 \%$ of sample students attended Econometrics and Macroeconomics, respectively; the remaining $48 \%$ were enrolled at Microeconomics.

\footnotetext{
${ }^{8}$ In the appendix of the paper we report the descriptive statistics for the sample of all 720 enrolled students.
} 
High School Grade ranges from 60 (the minimum passing grade) to 100 (the maximum grade), with a mean of 86.3. Students are almost equally spread between Lyceums (about 51\%) and Technical and Vocational Schools (49\%). Students are on average 20.5 years old.

We rescale all the students' grades on a $0-1$ scale. The Predicted Grade is on average 0.33 ; the mean of Grade Competition obtained by students at the mid-term exam is 0.41 , while the mean grade at the final exam, Grade Exam, (without bonus) is 0.46 . The correlation coefficients are 0.54 between Predicted Grade and Grade Competition and 0.55 between Predicted Grade and Grade Exam. 0.78 is the correlation between Grade Competition and Grade Exam. All the correlation coefficients are statistically significant at the 1 percent level.

\section{Participation in the Competition and Gender}

In this Section we firstly analyze the decision to join the tournament and, then, we focus on students' decision to effectively show up at the mid-term exam, once they knew their competitor's identity.

595 students, out of 720 enrolled to the courses involved in the experiment, joined the tournament. To investigate students' decision to participate in the experiment, we estimate a Linear Probability Model, using as dependent variable the dummy Non participant. Results are reported in Table 2.

In column (1) of Table 2 we use as explanatory variable only Female. We find that the coefficient on this variable is far from being statistically significant: the propensity to participate in the tournament is not different between males and females. In column (2) we enrich our specification by controlling for course dummies and in column (3) we add also controls for students' characteristics (High School Grade, Lyceum, Age). We always find that females are as likely as males to participate in the competition. Besides, we show that non-participation is positively related to Age and negatively related to the High School Grade: older students and students endowed with lower predetermined abilities are less likely to participate in the tournament. It is likely that these are students not attending regularly university courses.

Our findings, suggesting that females do not shy away from competition, may depend on the particular design of our experiment. In fact, as explained above, in order to disentangle the role of the taste for competition, we have tried to neutralize differences in other factors such as self-confidence, risk aversion and preferences for feedback on relative performance.

Since, as shown by the existing literature, self-confidence accounts for a large part of the gender gap in entry decisions, ${ }^{9}$ we have tried to influence students' beliefs about their probability of winning announcing them that the competition would occur between students of very similar ability, with an equal ex-ante probability of earning the highest bonus. Even if at this stage students did not know the identity of their competitor they were informed about this crucial rule of the tournament. As a consequence, even less selfconfident female students may have been reassured about the fact that an informed subject was matching

\footnotetext{
${ }^{9}$ See the works cited in Niederle and Vesterlud (2011).
} 
them with someone of comparable ability.

It is also worthwhile to notice that risk is not particularly relevant in our setting. In addition, participating in the tournament does not imply receiving feedback on relative performance that students could otherwise avoid. Finally, the task in which students were involved was not a male-stereotyped task.

Table 2. Participation in the Competition. Linear Probability Model. Dependent Variable: Non participant

\begin{tabular}{|c|c|c|c|}
\hline & (1) & (2) & (3) \\
\hline \multirow[t]{2}{*}{ Female } & 0.0096 & 0.0063 & 0.0217 \\
\hline & $(0.0283)$ & $(0.0279)$ & $(0.0280)$ \\
\hline \multirow[t]{2}{*}{ Macroeconomics } & & $0.0957 * * *$ & $0.1304 * * *$ \\
\hline & & $(0.0359)$ & $(0.0341)$ \\
\hline \multirow[t]{2}{*}{ Econometrics } & & 0.0175 & $-0.2133 * * *$ \\
\hline & & $(0.0324)$ & $(0.0428)$ \\
\hline \multirow[t]{2}{*}{ High School Grade } & & & $-0.0037 * *$ \\
\hline & & & $(0.0016)$ \\
\hline \multirow[t]{2}{*}{ Lyceum } & & & -0.0278 \\
\hline & & & $(0.0277)$ \\
\hline \multirow[t]{2}{*}{ Age } & & & $0.0546 * * *$ \\
\hline & & & $(0.0066)$ \\
\hline \multirow[t]{2}{*}{ Constant } & $0.1686^{* * *}$ & $0.1394 * * *$ & $-0.6162 * * *$ \\
\hline & $(0.0202)$ & $(0.0247)$ & $(0.1845)$ \\
\hline Observations & 720 & 720 & 720 \\
\hline R-squared & 0.000 & 0.012 & 0.116 \\
\hline
\end{tabular}

Notes: The Table reports OLS estimates. Standard errors (reported in parentheses) are corrected for heteroskedasticity. The symbols $* * *, * * *$ indicate that coefficients are statistically significant, respectively, at the 1,5 , and 10 percent level.

Then, we turn our attention on the decision of each student to effectively show up at the mid-term exam. In particular, we analyze whether students' decision not to take part in the competition, after having initially registered for it, has been influenced by the gender of the student against whom they had to compete.

At this aim, we estimate a Linear Probability Model considering as dependent variable the dummy Absent. Results are reported in Table 3. The estimates are run on the sample of 595 students registered for the experiment.

In the first specification of Table 3 we only control for student's predicted ability, the dummy Female and course dummies. We find again that the probability of not taking part in the competition does not differ according to gender. As expected, it depends negatively on the predicted grade. Similar results are found when we add additional controls for individual ability and for Age (column 2).

Our results, showing that females are as likely as males both to initially join the competitive tournament and to maintain this decision by effectively taking part in it, are in line with those found by Price (2010), who also fails to find gender differences in preference for competition. Interestingly in Price's study males and females were very similar in terms of self-confidence, which, as explained above, is likely to hold true also in our study. 
Table 3. The impact of competitor's gender on withdrawal decisions. Linear Probability Model. Dependent Variable: Absent

(2)

(3)

0.0012

Female

Female vs. Female

Female vs. Male

Male vs. Female

Predicted Grade

Econometrics

Macroeconomics

High School Grade

Lyceum (0.0249)

(0.0250)

Age

Constant

Observations

Observations

Adjusted R-squared

Diff. FF-FM

$p$-value

\subsection{5}

(0.0384)

$-0.0044$

(0.0367)

0.0021

(0.0373)

$-0.1502 * * *$ $(0.0487)$

$-0.1111 * * *$ (0.0288)

$-0.1288 * * *$ (0.0276)

$-0.1349 * *$

(0.0571)

$-0.1389 * *$

(0.0594)

$-0.1266 * * *$

(0.0275)

0.0001

(0.0014)

$-0.0427$

$(0.0259)$

0.0042

(0.0111)

$(0.0111)$
0.1451

(0.2498)

$-0.1544 * * *$

(0.0506)

$-0.1101 * * *$

(0.0291)

$-0.1289 * * *$

(0.0276)

$0.2136 * * *$
$0.2137 * * *$

595

0.049

0.049

Notes: The Table reports OLS estimates. Standard errors (corrected for heteroskedasticity) are reported in parentheses. The symbols $* * *, * *, *$ indicate that the coefficients are statistically significant at the 1, 5 and 10 percent level, respectively. In the last two rows of the Table it is reported the difference between (Female vs. Female) and (Female vs. Male) and its $p$-value.

In column (3), at the aim of investigating the role played by the competitor's gender in shaping withdrawal decision, we include among regressors dummies for the gender composition of the couple: Female vs. Female, identifying a female student competing against another female; Female vs. Male, identifying a female competing against a male, and Male vs. Female, identifying a male competing against a female opponent. The reference category is a male facing a male opponent.

None of these dummy variables attracts a statistically significant coefficient, implying that the opponent's gender does not significantly affect the withdrawal decision neither of males nor of females. The probability that a female competing with another female decides not to show up to the competition is not significantly different from the probability of being absent of a female competing against a male (this difference is reported in last row of Table 3, together with the corresponding $p$-value).

The same results hold true also in column (4) in which we add controls for a number of students' characteristics, i.e. Age, High School Grade and Lyceum.

Finally, we have also run separate regressions for high and low ability students (that is, students with a predicted grade, respectively, above and below the mean). As shown in columns (5) and (6), male and female 
students, both of high and low ability, are not affected by the gender of their competitor in deciding to compete in the tournament.

As far as control variables are concerned, we find that the Predicted Grade is an important determinant of the probability of withdrawing from the competition. The coefficient is negative and statistically significant in all the specifications considering the whole sample: students with a lower predicted grade are more likely to not show up at the tournament. This is probably related to the minimum threshold required to obtain the bonus: students with a lower predicted grade are less likely to reach this threshold. Once we control for this measure of ability, neither High School Grade nor Lyceum exert any statistically significant effect on the probability of being absent. The class attended significantly affects the decision to take part in the tournament: students taking Econometrics and Macroeconomics exams are significantly less likely than Microeconomics students to be absent the day of the competition.

All in all, our results suggest that the opponent's gender is not particularly relevant in inducing individuals to participate in a competitive environment. The taste for competition, ceteris paribus, does not seem to be related to one's opponent gender.

\section{Does Competitor's Gender Matter in Competitive Environments?}

In this Section we investigate whether male and female students perform differently in a competitive environment and whether their performance is affected by the gender of their opponent. We estimate the following linear regression model:

$$
\text { GradeCompetition }_{i}=\beta_{0}+\beta_{1} \text { GenderComposition }_{i}+\beta_{2} \text { Predicted Grade }_{i}+\beta_{3} X_{i}+\varepsilon_{i}
$$

where Grade Competition $_{i}$ is the percentage of correct answers provided by student $i$ at the tournament; Gender Composition ${ }_{i}$ is a vector of dummies to capture the gender composition of competing pairs or, alternatively, a dummy for female students; Predicted Grade $_{i}$ is the student's predicted grade, on the basis of which the competing students have been matched; $X_{i}$ is a vector of student's predetermined characteristics, cognitive ability, and courses dummies; $\varepsilon_{i}$ is an error term.

Table 4 reports OLS estimates for the impact of gender and competitor's gender on student's performance at the tournament. The first specification investigates the existence of gender differences in performance using the dummy Female, controlling only for Predicted Grade and for courses' dummies.

It emerges a positive and statistically significant relationship between the predicted grade and the percentage of correct answers given at the mid-term exam: the coefficient of Predicted Grade is 0.68 (10 percentage points more of predicted grade increase of 6.8 percentage points the effective performance) with a $t$-stat of 15: this makes us confident of the reliability of the predictor of ability we use. Students attending 
Econometrics and Macroeconomics courses obtain a grade lower than Microeconomics' students: this may be due to the fact that Microeconomics is a basic course for students enrolled at the first year of their academic career while Econometrics and Macroeconomics are more advanced courses which are taught during the second and third year of enrolment, respectively.

More importantly for our analysis, estimation results show that females perform better than males also under competitive pressure: in the tournament, a female obtained a score of correct answers that is on average 6.3 percentage points higher than the grade obtained by a male, with an effect that is statistically significant at the 1 percent level. This result is obtained even if we control for student's ability using Predicted Grade and holds true also in column (2) (but lower in magnitude) in which we control for additional measures of individual ability, such as High School Grade, Lyceum and Age. As regards these controls, High School Grade is positively and statistically significantly correlated with student's performance, while Age and Lyceum do not exert any statistically significant impact.

However, this finding does not necessarily imply that females are better than males in competitive environments, since females could be different from males for some unobservable characteristics that are not captured by our explanatory variables. To avoid this kind of problem, we will return to this issue in the next section, in which we will compare the performance of the same student in a competitive and in a noncompetitive setting.

We turn now our attention to the effect produced by the opponent's gender on student's performance at the tournament. At this aim, in the specification reported in columns (3) and (4) of Table 4, we add among controls our dummies Female vs. Female; Female vs. Male and Male vs. Female, leaving Male vs. Male as reference category. ${ }^{10}$

Results show that the gender of the competitor does not exert any statistically significant impact on the performance of the student: the performance of a female competing with another female does not differ in a statistically significant way from the performance obtained by a female competing against a male $(0.0634-$ $0.0596=0.0038$, with a $p$-value of 0.88 , see the last two rows of Table 4). Likewise, the performance of a male competing against a female does not significantly differ from that of a male competing with a male, the reference category (the coefficient on Male vs. Female is -0.003 , with a $p$-value of 0.91 ). The coefficients on these dummies confirm that - regardless of the competitor's gender - females tend to perform better than males.

In column (4) we estimate the same specification of column (3) by adding among controls students' personal characteristics and measures of cognitive abilities. The impact of the competitor's gender remains statistically not significant: neither males nor females perform differently when facing students of the opposite sex compared to when they face students of their own gender.

\footnotetext{
${ }^{10}$ An alternative but equivalent way to estimate these effects is to include among the explanatory variables the dummy Female, the dummy Female_Competitor, equal to one if the competitor is a female, and the interaction term between these two variables Female*Female_Competitor.
} 
Table 4. The impact of gender and competitor's gender on student's performance. OLS estimates. Dependent Variable: Grade Competition

\begin{tabular}{|c|c|c|c|c|c|c|}
\hline & (1) & (2) & (3) & (4) & $\begin{array}{c}(5) \\
\text { High Ability }\end{array}$ & $\begin{array}{c}\text { (6) } \\
\text { Low Ability }\end{array}$ \\
\hline Female vs. Female & & & $\begin{array}{c}0.0634 * * \\
(0.0282)\end{array}$ & $\begin{array}{c}0.0406 \\
(0.0286)\end{array}$ & $\begin{array}{c}0.0611 \\
(0.0427)\end{array}$ & $\begin{array}{c}0.0045 \\
(0.0420)\end{array}$ \\
\hline Female vs. Male & & & $\begin{array}{c}0.0596 * * \\
(0.0283)\end{array}$ & $\begin{array}{c}0.0394 \\
(0.0282)\end{array}$ & $\begin{array}{l}0.0825 * \\
(0.0438)\end{array}$ & $\begin{array}{l}-0.0016 \\
(0.0372)\end{array}$ \\
\hline Male vs. Female & & & $\begin{array}{l}-0.0030 \\
(0.0266)\end{array}$ & $\begin{array}{l}-0.0113 \\
(0.0266)\end{array}$ & $\begin{array}{c}0.0250 \\
(0.0424)\end{array}$ & $\begin{array}{l}-0.0596 * \\
(0.0329)\end{array}$ \\
\hline Predicted Grade & $\begin{array}{c}0.6849 * * * \\
(0.0454)\end{array}$ & $\begin{array}{c}0.5689 * * * \\
(0.0537)\end{array}$ & $\begin{array}{c}0.6848 * * * \\
(0.0454)\end{array}$ & $\begin{array}{c}0.5701 * * * \\
(0.0535)\end{array}$ & $\begin{array}{c}0.7025 * * * \\
(0.1123)\end{array}$ & $\begin{array}{c}0.6780 * * * \\
(0.1728)\end{array}$ \\
\hline Econometrics & $\begin{array}{c}-0.0536 * * \\
(0.0239)\end{array}$ & $\begin{array}{l}-0.0242 \\
(0.0471)\end{array}$ & $\begin{array}{c}-0.0532 * * \\
(0.0240)\end{array}$ & $\begin{array}{l}-0.0236 \\
(0.0472)\end{array}$ & $\begin{array}{l}-0.0774 \\
(0.0764)\end{array}$ & $\begin{array}{c}0.0976 \\
(0.0726)\end{array}$ \\
\hline Macroeconomics & $\begin{array}{c}-0.1049 * * * \\
(0.0223)\end{array}$ & $\begin{array}{c}-0.1109 * * * \\
(0.0223)\end{array}$ & $\begin{array}{c}-0.1048 * * * \\
(0.0224)\end{array}$ & $\begin{array}{c}-0.1108 * * * \\
(0.0223)\end{array}$ & $\begin{array}{c}-0.1277 * * * \\
(0.0338)\end{array}$ & $\begin{array}{c}-0.0907 * * * \\
(0.0302)\end{array}$ \\
\hline Female & $\begin{array}{c}0.0631 * * * \\
(0.0189)\end{array}$ & $\begin{array}{c}0.0464 * * \\
(0.0190)\end{array}$ & & & & \\
\hline High School Grade & & $\begin{array}{c}0.0049 * * * \\
(0.0012)\end{array}$ & & $\begin{array}{c}0.0049 * * * \\
(0.0012)\end{array}$ & $\begin{array}{l}0.0033 * \\
(0.0017)\end{array}$ & $\begin{array}{c}0.0028 \\
(0.0019)\end{array}$ \\
\hline Lyceum & & $\begin{array}{c}0.0169 \\
(0.0189)\end{array}$ & & $\begin{array}{c}0.0173 \\
(0.0190)\end{array}$ & $\begin{array}{c}0.0034 \\
(0.0265)\end{array}$ & $\begin{array}{c}0.0045 \\
(0.0263)\end{array}$ \\
\hline Age & & $\begin{array}{l}-0.0073 \\
(0.0081)\end{array}$ & & $\begin{array}{l}-0.0072 \\
(0.0082)\end{array}$ & $\begin{array}{l}-0.0204 \\
(0.0134)\end{array}$ & $\begin{array}{l}-0.0084 \\
(0.0114)\end{array}$ \\
\hline Constant & $\begin{array}{c}0.1918 * * * \\
(0.0203)\end{array}$ & $\begin{array}{l}-0.0504 \\
(0.1922)\end{array}$ & $\begin{array}{c}0.1933 * * * \\
(0.0251)\end{array}$ & $\begin{array}{l}-0.0489 \\
(0.1928)\end{array}$ & $\begin{array}{c}0.3119 \\
(0.3398)\end{array}$ & $\begin{array}{c}0.1238 \\
(0.2690)\end{array}$ \\
\hline Observations & 533 & 533 & 533 & 533 & 266 & 267 \\
\hline Adjusted R-squared & 0.334 & 0.352 & 0.331 & 0.350 & 0.223 & 0.119 \\
\hline $\begin{array}{l}\text { Diff. FF-FM } \\
p \text {-value }\end{array}$ & & & $\begin{array}{l}0.0038 \\
0.8853\end{array}$ & $\begin{array}{l}0.0012 \\
0.9648\end{array}$ & $\begin{array}{c}-0.0214 \\
0.5250\end{array}$ & $\begin{array}{l}0.0061 \\
0.8839\end{array}$ \\
\hline
\end{tabular}

Notes: The Table reports OLS estimates. Standard errors (reported in parentheses) are corrected for heteroskedasticity. The symbols $* * *, * *, *$ indicate that coefficients are statistically significant, respectively, at the 1,5 , and 10 percent level. In the last two rows of the Table it is reported the difference between (Female vs. Female) and (Female vs. Male) and its $p$-value.

Finally, we run the same specification reported in column (4) separately for high ability students (column 5), that is, students with a predicted grade higher than the average (within each course), and for low ability students (column 6), whose predicted grade is lower than the average. Again, we do not find that one's opponent gender produces any statistically significant effect on performance neither for high ability students nor for students with lower ability. Only low ability males seem to perform slightly worse when competing against a female than when facing another male: a female competitor reduces the performance of a male by almost 6 percentage points, with an effect that is statistically significant at the $10 \%$ level. Among high ability students, females tend to perform better than males, while the gender difference disappears for low ability students (not reported). 


\section{Comparing Performance in Competitive and Non-Competitive}

\section{Settings}

In this Section we investigate whether performing in competitive or non-competitive settings affects the outcomes of males and females in a different way.

While in the tournament at the mid-term exam students were competing against each other to obtain the highest bonus, at the final exam they performed under a non-competitive scheme, with a sort of piecerate system, since their grade is defined according to the number of correct answers, regardless of performance of other students. In fact, final grades are not assigned in these courses by "grading on a curve".

The final exam was taken by students at the end of the course in three different dates (in June, July and September). Students have the possibility to retake the exam, but, in these cases, we only consider the performance at the first exam they have taken. ${ }^{11}$

We estimate a model of performance at the exam - using as a dependent variable Grade Exam - to check the existence of gender differences in non-competitive settings. As mentioned above, the performance at the final exam is highly correlated $(\rho=0.78)$ to the performance at the mid-term exam competition.

OLS estimates are reported in Table 5. We find that females performed slightly better than males at the final exam when we only control for Predicted Grade (column 1), but there is no gender difference in performance when in column (2) we include controls for pre-determined students' characteristics (High School Grade, Lyceum, Age).

In column (3) we also control for the Bonus Points ${ }^{12}$ obtained by students at the tournament since these points represent an additional measure of ability. ${ }^{13}$ It turns out that students who gained bonus points perform better than others. Again, also controlling for bonuses, we find that males and females obtained the same performance.

\footnotetext{
${ }^{11}$ Using the average outcome obtained by a student in case of re-sitting lead to the same results.

${ }^{12}$ The variable Bonus takes values 0,2 and 5, respectively, for students who did not reach the minimum threshold, who lost and who won the competition.

${ }^{13}$ Moreover, it could be that having obtained bonus points at the mid-term exam changes students' incentives: they might be induced to study either less or more. In fact, on the one hand, students who have obtained bonus points enjoy a small advantage (ceteris paribus, they are more likely than other students to reach any target grade at the exam). On the other hand, they might be induced to study harder since the bonus points will be lost if they will not reach the minimum passing grade (i.e.18) within September.
} 
Table 5. Performance in a Non-Competitive Setting. OLS estimates. Dependent Variable: Grade Exam

(1)

\begin{tabular}{|c|c|c|c|c|c|}
\hline \multirow{3}{*}{ Female } & & & & High Abil. & Low Abil. \\
\hline & $0.0403 * *$ & 0.0239 & 0.0029 & 0.0041 & 0.0251 \\
\hline & $(0.0195)$ & $(0.0202)$ & $(0.0169)$ & $(0.0289)$ & $(0.0256)$ \\
\hline Predicted Grade & $\begin{array}{c}0.7580 * * * \\
(0.0439)\end{array}$ & $\begin{array}{c}0.6710 * * * \\
(0.0519)\end{array}$ & $0.5185 * * *$ & $0.7265^{* * *}$ & $\begin{array}{l}1.2516^{* * * *} \\
0.1600)\end{array}$ \\
\hline High School Grade & & $\begin{array}{c}0.0044 * * * \\
(0.0012)\end{array}$ & $\begin{array}{c}0.0025^{* *} \\
(0.0011)\end{array}$ & $\begin{array}{l}0.0034 * \\
(0.0019)\end{array}$ & $\begin{array}{l}-0.0004 \\
(0.0019)\end{array}$ \\
\hline Lyceum & & $\begin{array}{c}0.0104 \\
(0.0198)\end{array}$ & $\begin{array}{c}0.0028 \\
(0.0165)\end{array}$ & $\begin{array}{l}-0.0090 \\
(0.0273)\end{array}$ & $\begin{array}{l}-0.0187 \\
(0.0260)\end{array}$ \\
\hline Age & & $\begin{array}{c}0.0042 \\
(0.0085)\end{array}$ & $\begin{array}{c}0.0057 \\
(0.0081)\end{array}$ & $\begin{array}{l}-0.0168 \\
(0.0151)\end{array}$ & $\begin{array}{c}0.0066 \\
(0.0097)\end{array}$ \\
\hline Bonus Points & & & $\begin{array}{c}0.0569 * * * \\
(0.0040)\end{array}$ & & \\
\hline Constant & $\begin{array}{c}0.2544 * * * \\
(0.0260) \\
\end{array}$ & $\begin{array}{l}-0.1696 \\
(0.1961) \\
\end{array}$ & $\begin{array}{c}-0.1381 \\
(0.1806) \\
\end{array}$ & $\begin{array}{c}0.3959 \\
(0.3748) \\
\end{array}$ & $\begin{array}{c}0.0221 \\
(0.2199) \\
\end{array}$ \\
\hline Observations & 533 & 533 & 533 & 226 & 307 \\
\hline Adjusted R-squared & 0.346 & 0.358 & 0.541 & 0.255 & 0.204 \\
\hline
\end{tabular}

Notes: The Table reports OLS estimates. In all the specifications we control for course and date of exam dummies. Standard errors (reported in parentheses) are corrected for heteroskedasticity. The symbols ***, **, * indicate that coefficients are statistically significant, respectively, at the 1,5 , and 10 percent level.

No gender differences in performance emerge also when we split the sample considering separately high and low ability students (columns 4 and 5).

To investigate whether gender differences in performance arise as a result of the type of setting in which students interact, we stack the data at exam level and consider two observations for each student regarding his/her performance at the competitive and non-competitive setting, respectively.

To this aim, we build the variable Grade that takes the values of Grade Competition for the performance in the tournament and Grade Exam for the non-competitive setting and estimate a model for Grade, with individual fixed effects. ${ }^{14}$ In this way, we are comparing the performance of the same student under two different settings.

OLS estimates using individual fixed effects are reported in Table 6. In column (1) we only consider the dummy Competition (equal to one for the tournament): on average, students tend to perform worse in the competitive setting (about 4.2 percentage points less). This result could also be due to better learning in the subsequent final exam.

With individual fixed effects we cannot estimate the dummy Female, but we can verify if females perform differently from males in competitive settings by estimating in column (2) a model with the interaction Female*Competition. The coefficient of this interaction $(0.024)$ is positive although not significant at the conventional levels ( $p$-value $=0.12$ ): females tend to perform at the same level as males (or, if anything, slightly better) in competitive settings. We find the same result in columns (3) and (4) in which we consider, respectively, high and low abilities students. In particular, among high abilities students, the performance of females tends to be better than males.

\footnotetext{
${ }^{14}$ An equivalent way to identify the effect of interest is to estimate a model using as a dependent variable the difference (Grade Competition - Grade Exam) for each student.
} 
Table 6. Comparison of Performance in Competitive and Non-competitive settings. Estimates with Individual Fixed Effects. Dependent Variable: Grade

\begin{tabular}{lcccc}
\hline \hline & $(1)$ & $(2)$ & $(3)$ & $(4)$ \\
& & & High Ability & Low Ability \\
\hline Competition Setting & $-0.0424 * * *$ & $-0.0551^{* * *}$ & $-0.0824 * * *$ & $-0.0361^{* *}$ \\
& $(0.0077)$ & $(0.0114)$ & $(0.0188)$ & $(0.0140)$ \\
Female*Competition & & 0.0244 & $0.0425^{*}$ & 0.0165 \\
& & $(0.0155)$ & $(0.0236)$ & $(0.0209)$ \\
Constant & $0.4569 * * *$ & $0.4569 * * *$ & $0.6012 * * *$ & $0.3215 * * *$ \\
& $(0.0039)$ & $(0.0039)$ & $(0.0057)$ & $(0.0052)$ \\
\hline Observations & 1066 & 1066 & 516 & 550 \\
Adjusted R-squared & 0.053 & 0.056 & 0.097 & 0.026 \\
\hline \hline
\end{tabular}

Notes: The Table reports OLS estimates with individual fixed effects. Standard errors (reported in parentheses) are corrected for heteroskedasticity and allowing for clustering at the student level. The symbols ***, **, * indicate that coefficients are statistically significant, respectively, at the 1,5 , and 10 percent level.

This result confirms that females are not averse to competition, when other possible psychological determinants (self-confidence, risk-aversion, preference for feedback, etc.) are neutralized.

\section{Concluding Remarks}

A recent strand of the economic literature has tried to explain the male-female gap in labor market outcomes considering differences in preferences and psychological attitudes. One prominent factor that has been considered is that females dislike competitive environments and perform worse in competition: their attitudes towards competitive settings may account for their low presence in higher paying jobs and in top managerial and political positions.

Many laboratory studies show that women tend to prefer less competitive settings, to perform worse than men under competitive pressure and to show a more marked disadvantage when they compete against men. Field experiments have produced more mixed results.

However, it is not clear whether this behavior is due to a distaste for competition or is related to other factors typically influencing competition-entry and performance, such as self-confidence, attitudes toward risk or preference for feedback on relative performance.

Our paper provides new evidence on the gender gap in competitive environments relying on a field experiment involving undergraduate students. We introduced competition in a real life situation by organizing a mid-term exam under the form of a tournament in which students compete in pairs to gain a maximum of 5 points to add to the mark obtained at their final exam, which is instead performed under a piece-rate scheme.

At the aim of disentangling the role played by gender differences in "taste for competition" in explaining differences in competitive settings we have designed the experiment to neutralize gender differences in self-confidence (students know they have the same ability of their opponent), in risk attitudes 
(the choice they made is practically risk-free) and in preferences for relative performance feedback (since feedback on performance is received in any setting).

We find that females are as likely as males both to initially join the competitive tournament and to maintain this decision by effectively taking part to it. Considering individual performance we do not find any evidence of females' under-performance under competitive pressure. Importantly, we show that the gender of the competitor does not affect performance, neither for males nor for females.

Finally, by comparing each student's performance in the tournament (under competition) and at the final exam (a non-competitive setting), we find that the relative performance of males and females is typically not affected by the reward scheme: if anything, females tend to perform better in the tournament than in the non-competitive scheme.

Therefore, in contrast to many laboratory studies, we find that males and females do not differ much in terms of taste for entering in competitive environments and in their ability to perform well under competitive pressure. Since in our experiment we tried to neutralize other more general psychological differences among males and females, our results suggest that the differences observed in competitive environments is probably driven by gender differences in psychological attitudes, such as self-confidence, risk attitudes and preferences for feedback.

\section{References}

Altonji, J. and Blank, R., (1999), "Race and gender in the labor market", in Ashenfelter O. and Card, D., eds.), Handbook of Labor Economics, Vol. 3C, pp. 3143-259, Amsterdam: North-Holland.

Antonovics, K., Arcidiacono, P., Walsh, R., (2009), "The effects of gender interactions in the lab and in the field", Review of Economics and Statistics 91 (1), 152-163.

Balafoutas, L. and Sutter, M., (2012), "Affirmative Action Policies Promote Women and Do Not Harm Efficiency in the Laboratory," Science, 335 (6068), pp. 579-582.

Bertrand M, Hallock KF. (2001), "The gender gap in top corporate jobs", Industrial and Labor Relation Review, 55:3-21.

Bertrand, M., (2011), "New Perspectives on Gender", Handbook of Labor Economics, vol. 4b, Amsterdam: North-Holland.

Blau, F., Kahn, L., (2006), "The US gender pay gap in the 1990s: slowing convergence". Industrial and Labor Relations Review 60, 45-66.

Cason T., Masters W., Sheremeta R. (2010), "Entry into winner-take-all and proportional-prize contests: an experimental study", Journal of Public Economics, 94, pp. 604-11.

Cotton, C., McIntyre, F. and Price, J. (2013), "Gender Differences in Repeated Competition Evidence from School Math Contests", Journal of Economic Behavior and Organization, Vol. 86, 2013.

Croson, R., and U. Gneezy, (2009), "Gender Differences in Preferences." Journal of Economic Literature, 47 (2), pp. 448-74.

Dargnies, M. P. (2009), "Does team competition eliminate the gender gap in entry in competitive environments?", Working Paper, Document de Travail du Centre d'Economie de la Sorbonne 2009.06.

Datta Gupta, N., Poulsen, A., \& Villeval, M. C. (2013). "Gender matching and competitiveness: experimental evidence", Economic Inquiry, 51(1), 816-835.

De Paola, M. and Scoppa, V., (2011), "Frequency of Examinations and Student Achievement in a Randomized Experiment", Economics of Education Review, 30, 6, pp. 1416-1429.

Delfgaauw, J. Dur, R., Sol, J. and Verbeke, W., (2013), "Tournament Incentives in the Field: Gender 
Differences in the Workplace, Journal of Labor Economics, Vol. 31, No. 2, pp. 305-326

Gneezy U., Leonard L., List J. (2009), "Gender differences in competition: evidence from a matrilineal and a patriarchal society", Econometrica, 77:1637-64

Gneezy, U., Niederle, M., Rustichini, A., (2003), "Performance in competitive environments: gender differences", Quarterly Journal of Economics, 118, 1049-1074.

Gneezy, U., Rustichini, A., (2004), "Gender and competition at a young age", American Economic Review, 94 (2), 377-381.

Goldin C., Katz LF, Kuziemko I. (2006), "The homecoming of American college women: the reversal of the college gender gap", Journal of Economic Perspectives, 20(4), pp.133-56.

Healy, A., and Pate, J. (2011), “Can Teams Help to Close the Gender Competition Gap?", Economic Journal $121.555,1192-1204$.

Jurajda S, Munich D. (2011), "Gender gap in performance under competitive pressure: Admission to Czech Universities", American Economic Review: Papers \& Proceedings 2011, 101:3, 514-518.

Lavy, V. (2012). "Gender Differences in Market Competitiveness in a Real Workplace: Evidence from Performance-based Pay Tournaments among Teachers", Economic Journal......

Niederle, M., Vesterlund, L. (2007), "Do women shy away from competition? Do men compete too much?" Quarterly Journal of Economics, 122 (3), 1067-1101.

Niederle, M., Vesterlund, L. (2008). "Gender differences in competition”, Negotiation Journal 24 (4), $447-$ 463.

Niederle M, Vesterlund L. (2010), "Explaining the gender gap in math test scores: the role of competition", Journal of Economic Perspectives, 24(2):129-44.

Niederle, M., Vesterlund, L. (2011), "Gender and Competition", Annual Review of Economics, 3, 601-630.

Ors, E., Palomino, F. Peyrache, E., (2013) “Performance Gender Gap: Does Competition Matter?”, Journal of Labor Economics, Vol. 31, 3, pp. 443-499.

Paserman D. (2010), "Gender differences in performance in competitive environments: evidence from professional tennis players", Work. Pap., Boston Univ.

Price, C. (2010). "Do Women Shy Away From Competition? Do Men Compete Too Much? : A (Failed) Replication", Working Paper University of Southern Indiana.

Sutter M, Rutzler D. (2010), "Gender differences in competition emerge early in life", IZA Discussion Paper, No. 5015, Bonn, Germany.

Shurchkov O. (2011), "Under pressure: gender differences in output quality and quantity under competition and time constraints", Journal of the European Economic Association, 10(5), 1189-1213.

Wozniak D., Harbaugh W., Mayr U. (2010), "Choices about competition: differences by gender and hormonal fluctuations, and the role of relative performance feedback", Working Paper, University of Oregon. 


\section{APPENDIX}

Table 7. Descriptive Statistics on all enrolled students at the courses of Microeconomics, Macroeconomics and Econometrics (academic year 2012-2013)

\begin{tabular}{lccccc}
\hline \hline Variables & Obs. & Mean & Std. Dev. & Min & Max \\
\hline Female & 720 & 0.522 & 0.500 & 0 & 1 \\
Macroeconomics & 720 & 0.274 & 0.446 & 0 & 1 \\
Econometrics & 720 & 0.268 & 0.443 & 0 & 1 \\
High School Grade & 720 & 85.874 & 9.787 & 60 & 100 \\
Lyceum & 720 & 0.497 & 0.500 & 0 & 1 \\
Age & 720 & 20.768 & 2.963 & 18 & 44 \\
\hline \hline
\end{tabular}

